Instructions for authors, subscriptions and further details:

\title{
http://mcs.hipatiapress.com
}

\section{Beckett's Masculinity}

Patricia Melgar ${ }^{1}$

1) University of Girona

Date of publication: February $21^{\text {th }}, 2017$

Edition period: February 2017-June 2017

To cite this article: Melgar, P. (2017). Beckett's masculinity [Review of the book]. Masculinities and Social Change, 6(1), 91-92. doi:

10.17583/MCS.2017.2565

To link this article: http://dx.doi.org/10.4471/MCS.2017.2565

PLEASE SCROLL DOWN FOR ARTICLE

The terms and conditions of use are related to the Open Journal System and to Creative Commons Attribution License (CC-BY). 
MCS - Masculinities and Social Change Vol. 6 No. 1 February 2017

pp. 91-92

\section{Reviews (I)}

Jennifer M. Jeffers. (2016). Beckett's Masculinity. New York: Springer. ISBN: 978-1-349-37905-7

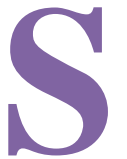

amuel Beckett es uno de los exponentes más importantes de la literatura contemporánea del siglo XX, de hecho su obra es un claro ejemplo de la influencia que puede tener el teatro y la dramaturgia en la sociedad de la época. Su legado se sitúa dentro del existencialismo literario y una de sus principales contribuciones y más reconocida a nivel internacional es Esperando Godot. En el libro Beckett's Masculinity se realiza un análisis de la obra del escritor de forma diferente a previos análisis ya que en este caso se hace hincapié en la construcción de la masculinidad que se vislumbra en sus libros.

En el libro en cuestión se realiza una breve introducción al impacto que ha tenido la escritura de Beckett en diferentes personalidades de la época del mundo de la filosofía, la música y la literatura. Entre estos impactos Beckett señala los realizados a filósofos y pensadores como Jacques Derrida, Michel Focault, Theodor Adorno y Harold Pinter. Además en esta introducción el libro pone de relieve las excentricidades sexuales que aparecen en las obras de Beckett que significan un replanteamiento de las normas de género de la época así como la definición de la masculinidad. Para la autora de Beckett's Masculinity este desarrollo se debe sobre todo al deseo de dar una respuesta al contexto social de su época y a la normatividad que en él se definía. En este sentido se destaca el papel destacado que tuvo la construcción de Irlanda como un estado libre principalmente influencia por la religión protestante.

El libro se divide en siete capítulos, en el Capítulo 1 se pone de manifiesta la influencia, anteriormente mencionada, de la creación del Estado libre de Irlanda y la religión protestante. En este capítulo se destaca el papel de la familia patriarcal en la obra de Beckett así como la

2017 Hipatia Press

ISSN: 2014-3605

DOI: $10.17583 / \mathrm{MCS} .2017 .2565$ 


\section{Melgar-Beckett's masculinity [Book Review]}

constatación de la pérdida de los privilegios masculinos hegemónicos y de la figura paterna en el entorno social de la época. En el siguiente capítulo el énfasis se pone en los viajes de ida y vuelta a Irlanda y la relación que ello tiene en los procesos de emasculación y de la construcción de las identidades de género.

En el Capítulo 3 se describe la influencia de la figura paterna en las primeras obras de Beckett, y ligado a ello el planteamiento relacionado a las representaciones de género impuestas por Occidente. Para la autora de Beckett's Masculinity los primeros trabajos del escritor significan un desafío a la idea preconcebida que los hombres y las mujeres tienen una identidad estrictamente ligada a la naturaleza. En el Capítulo 4 el foco de atención son las obras Esperando Godot y Endgame donde se visibiliza un interés en explicar el fracaso del patriarcado en occidente, su decadencia y caída. La imposibilidad de retorno es de hecho unos de los aspectos que se manifiestan en Endgame. Por otro lado, en el Capítulo 5 se analizan aquellas obras en las que Beckett presenta una nostalgia del pasado, queriendo y deseando un retorno a la masculinidad de base anglo-irlandesa.

En los dos últimos capítulos se vuelve a ahondar en como al dramaturgo, a través de sus obras, realiza de forma concienzuda un cuestionamiento importante a las expectativas de género de su época.

Patricia Melgar, University of Girona patricia.melgar@udg.edu 